\title{
SAASQUALITY - A METHOD FOR QUALITY Evaluation OF SOFTWARE AS A SERVice (SAAS)
}

\author{
Nemésio Freitas Duarte Filho ${ }^{1}$, Clarindo Isaias Pereira da Silva e Pádua ${ }^{1}$, Paulo \\ Henrique de Souza Bermejo ${ }^{2}$, Andre Luiz Zambalde ${ }^{2}$, Urlan Salgado de Barros ${ }^{3}$ \\ ${ }^{1}$ Institute of Mathematical Sciences/Federal University of Minas Gerais \\ nemesiofreitas@gmail.com, clarindo@dcc.ufmg.br \\ ${ }^{2}$ Department of Computer Science/Federal University of Lavras. \\ bermejo@dcc.ufla.br, zamba@dcc.ufla.br \\ ${ }^{3}$ Department of Information/Federal University of Paraná. \\ urlancomp@gmail.com
}

\begin{abstract}
The market for software products offered as a service (SaaS) is growing steadily and has attracted suppliers from different segments of the global IT market. However, the use of the SaaS products brings a range of challenges, both in the organizational, cultural and technological areas. A difficulty that exists today is the lack of methods and models for assessing the quality of these products. This document presents a method to assess the quality of a software product offered as a service, named SaaSQuality. The proposed method has a quality model appropriate to the SaaS context, based on standards and models of software quality (ISO 9126) and models for IT management (ITIL and COBIT). The experimental results obtained through a case study show that the method offers suitable assessment practices for Software as a Service.
\end{abstract}

\section{KEYWORDS}

Software Quality. Software as a Service. Quality Management Services. Methods of Evaluation. Models for IT Management.

\section{INTRODUCTION}

Software quality has the objective to ensure conformity with software requirements. It means that a software product needs to attend to both explicit and implicit specifications, which this product is offered as a package or a service (SaaS - Software as a Service). Therefore, the final goal is ensure a product that satisfies all client's expectations [1].

Software development companies are worried about the quality excellence of their products, due to growth of organizations exigency. Nowadays, software product is a critical tool, and its quality requirements become key criteria's in software acquisition [2, 3]. It reflects directly on the mission and objectives of organizations business.

In this context, Software as a Service has been gaining popularity in organizations. The success of those products depends on functional and non-functional requirements [4]. These attributes help define the quality in a software product. However, the difficulty to establish and use quality criteria is linked with the complication on associate measurable requirements of physical products for software product [5]. 
SaaS is a new paradigm based on software delivery, which client organizations pay not for the ownership, but for the use of software. Therefore, software companies have to maintain and to evolve software, and they also need to assist problems related to technical support. Due to market's concurrence, many software companies are already applying this new paradigm. However, those companies have troubles mainly in ensure the quality of their final products, considering that SaaS is a new and incipient paradigm [6].

Only a few works approach definitions and impacts of quality attributes related to Software as Service product. In consequence, there's no evidence in scientific research about methods, models and metrics which provide a practical and efficient assessment of quality in SaaS products.

Many assessment methods of quality in software products are ineffective in relation to paradigm SaaS, mainly to not provide a correct set of quality attributes. An efficient attribute set may possess features and sub-features showing its scope and applicability. Moreover, it needs to show its positive and negative impacts in front of applications [6,7].

\section{RELATED WORK}

Dubey \& Wagle [8] show the main problems and concerns encountered on SaaS systems which have been found by organizations. Many of those problems can directly affect the quality of products and impact on other factors, such as functional and commercial aspects, conformity, and so on. Even analyzing the main concerns about this new paradigm, Dubey \& Wagle [8] do not present metrics and criteria's to auxiliary and to contribute in a practical evaluation of those problems. However, the analysis made in Dubey \& Wagle [8] with the definition of main problems contributes to this work, mainly in elaboration of a specific quality model to SaaS.

Another work linked to quality of SaaS systems is O'Brien et al. [9]. In that work, the authors make an analysis between a service oriented architecture (SOA) and quality of software attributes. That work is motivated by software architecture, due to SOA be an important factor in business compliance of organizations and computational systems. Furthermore, one of the objectives of O'Brien et al. [9] is to examine how a SOA supports quality attributes, such as availability, security, confiability, portability and interface, analyzing questions and problems related to them. The authors do not approach the creation of a method or model that could turn possible the practical application of these quality attributes. However, they identify features linked to software products and TI services, integrating perfectly to SaaS paradigm.

Following the same reasoning of previously researches, in Havelka et al. [10] is proposed an empirical study involving users of IT area. The aim of this study is to identify critical factors which can cause impact on both positive and negative manner on SaaS. The factors identified by the users were integrated in a questionnaire instrument to raise up evidences about the true impact of aspects approached. The study also identified others impelling factors, however, without relevance guarantee due to the research has been made considering only the user's opinion and knowledge.

Jureta et al. [11] follows the same reasoning of previously researches, but enters in aspects linked on a method that helps the quantification of quality in SaaS systems. In that work, the authors perform analysis on ISO 9126 and ISO 20000, proposing a new quality method entitled QVDP (Quality-Value-Dependency-Priority). The Research takes in consideration that SaaS products have different perspectives in relation to the conventional software's quality. For example, features of portability, support, personalization, and so on.

In the work by Cancian [12] was proposed a development process of SaaS systems. Development process is one of the main factors that can cause impact directly on final quality of those systems. Based on a few requirements of quality, Cancian [12] proposes a reference guide to evaluate 
development process of SaaS system. Furthermore, the author also performed a synthesis and analyze of requirements, mapping them in relation to standards and models of reference existed in literature. The research made by Cancian [12] has neither a practical application nor a real case study, but it shows a fundamental complete guide in reference to process evaluation of development in SaaS systems.

Cancian et al. [13] proposes a generic structure of SLA (Service Level Agreement) which defines quality items more adequate to SaaS. The author observed the necessity of a clear understandment associated to appointments firmed between a supplier and a client of SaaS solutions. Beyond the generic structure, Cancian et al. [13] also identifies important quality requirements that must be observed on SaaS model, mainly in SLAs. SLAs are important to guarantee the quality due to have a higher security on a service agreement.

In The work of Rosenberg et al. [14], it was found that the development of products SaaS is a difficult task and that is prone to errors, is difficult even ensure a good quality in its final product. For this reason it has been proposed in the work an automated composition of services called CaaS (Composition as a Service), in which facilitates the rapid development in small applications geared to services, guaranteeing greater efficiency during the development and greater internal quality of the software, generating an standardization in its architecture and in its source code.

In another context, linked with the quality of services of IT, Silva et al. [15] drawn up a proposal in order to analyze the administration of the services Information technology (IT) in companies where the strategic function it is vital for the competitiveness of business.

Miguel \& Salomi [16] in their research, showed a review in the literature on the main models and concepts that are proposed for the measurement of the quality of external services. The review has had an analytical basis, thematic, historical and bibliographic. After making presentations of the models more efficient and used, a comparison between them has been carried out by showing its main features.

According to results, Miguel \& Salomi [16] concluded that do not exist a consensus in literature about which model is more appropriated to measure the quality of IT service. Furthermore, there are question even not answered, such as, the causality relation between quality of IT services and customers satisfaction.

The Table 1 shows a summary of related work, identifying the relationship with quality aspects in relation to paradigm SaaS, for example, Method Evaluation; Quality Model; Evaluation Process; Requirements Analysis; and Systematic Review.

Table 1. Summary of related work

\begin{tabular}{|l|l|l|c|c|c|}
\hline Related Work & $\begin{array}{l}\text { Method } \\
\text { Evaluation }\end{array}$ & $\begin{array}{l}\text { Quality } \\
\text { Model }\end{array}$ & $\begin{array}{l}\text { Evaluation } \\
\text { Process }\end{array}$ & $\begin{array}{l}\text { Requirements } \\
\text { Analysis }\end{array}$ & $\begin{array}{l}\text { Systematic } \\
\text { Review }\end{array}$ \\
\hline $\begin{array}{l}\text { Dubey \& Wagle } \\
\text { [8] }\end{array}$ & & $\mathbf{x}$ & & $\mathbf{x}$ & $\mathbf{x}$ \\
\hline $\begin{array}{l}\text { O'Brien et al. } \\
\text { [9] }\end{array}$ & & & & $\mathbf{x}$ & $\mathbf{x}$ \\
\hline $\begin{array}{l}\text { Havelka et al. } \\
{[10]}\end{array}$ & & $\mathbf{x}$ & & $\mathbf{x}$ & $\mathbf{x}$ \\
\hline Jureta et al. [11] & $\mathbf{x}$ & $\mathbf{x}$ & & $\mathbf{x}$ & $\mathbf{x}$ \\
\hline $\begin{array}{l}\text { Cancian [12] } \\
\text { Cancian et al. } \\
{[13]}\end{array}$ & & & & & $\mathbf{x}$ \\
\hline $\begin{array}{l}\text { Rosenberg et al. } \\
\text { [14] }\end{array}$ & $\mathbf{x}$ & & $\mathbf{x}$ & &
\end{tabular}




\begin{tabular}{|l|l|l|l|l|l|}
\hline Silva et al. [15] & & $\mathbf{x}$ & & $\mathbf{x}$ & $\mathbf{x}$ \\
\hline Miguel \& & & & $\mathbf{x}$ & $\mathbf{x}$ \\
Salomi [16] & & & & \\
\hline
\end{tabular}

\section{RESEARCH METHODOLOGY}

This research is classified as qualitative and technology nature, focusing on objective exploratory, using case study procedures and basing your materials and methods on documental and bibliography researches $[17,18]$. The methodology process followed by this work possesses four phases.

1-Conception and preparation of research: The first phase includes the conception and initial aspects to realization of research. The problem's definition takes in consideration necessities of research environment, verifying if efforts are valid and relevant in relation to the lack of a practical and efficient method which assesses the quality of a SaaS product.

2-Preliminar results and analyses: In this phase, are realized analyses and studies relative to characteristics and quality requisites turned to paradigm SaaS, enabling the construction of a specific quality model to SaaS. The first phase was carried out the analysis of requirements in relation to the quality of software, covering studies of norms and standards of quality, providing analysis of quality criteria had been expected in a product of conventional software. This analysis made possible to identify which characteristics have applicability and purpose within systems SaaS.

At the same time has been carried out an analysis of requirements in relation to the quality of IT services. Frameworks and guides to good practice of management of service for IT where used with purpose to raise and analyze at quality criteria which can be found also in Software as a Service, remembering that SaaS have similar characteristics of a conventional system and IT services [4].

After the analysis, it was carried out a survey of quality requirements to the context SaaS, having as objective raise and integrate in a single set criteria and requirements of quality for a product SaaS, enabling their use in a method of evaluation. The integration was made using comparisons and definitions of applicability on the basis of the standard ISO/IEC 9126 [19], ITIL v3 [20] and COBIT 4.1 [21], in order to identify the characteristics of quality more relevant to the context SaaS. After the identification and integration of the criteria, there has been a complementation and prioritization of these characteristics, by means of a search of 85 people related to the SaaS paradigm (entrepreneurs, experts and researchers), offering greater complementation and reliability the characteristics that have been raised.

3-Validation and improvements in the method: This stage makes reference to the beginning of the study of the case, where it has for objective the validation of the method proposed, together with the model of quality. Still at this stage a process of evaluation has been defined, and also a stage of continued improvement for the SaaSQuality. After the definition of the characteristics of quality to be used by the SaaSQuality, there was the need to mapping all the characteristics in attributes measurable, enabling its measurement and scoring. This mapping has enabled the preparation on a list of verification (checklist), enabling a practical assessment of the quality requirements.

For the practical application of the method, there was the need to set up an evaluation process that can be repeatable, reproducible, impartial and objective. The process of evaluation of the SaaSQuality was based on the standard ISO/IEC 14598 [22], but some changes and adjustments 
have been made order to better match to the products SaaS, together with the roles played by the actors in the process.

On end of this phase has been carried out the validation and improvements in SaaSQuality by means of a study of the case. The study of the case is important, because it shows in a real environment the objective achieved, limitations and possible improvements, seeking validate the work performed. For the conduct of the study of the case, were performed evaluations on the product "SalesForce CRM Sales" on the basis of guidelines e metric of the SaaSQuality method.

4-Checks and Final Results: at this stage results have been achieved by means of a comparison, together with checks on the partial results obtained and published in the scientific community [23], specifically in the area of "Quality of Software". The method SaaSQuality was submitted to a comparison with a method of evaluation the quality conventional, in the case the MEDE-Pros, to complement its validation. This comparison showed several points which are not discussed or assessed by conventional methods, together with some limitations.

\section{QUALITY MODEL FOR SAASQUALITY}

In accordance with the authors $[10,11,24,25]$, so that the application of a method of evaluation will be efficient it is necessary that he it is based or contains a model of quality specific to the context of their applications.

The authors of this work neither found in the literature nor in the international standards, models of quality that envisage properly the characteristics of quality in a system SaaS. In the face of this particular characteristic was necessary the proposal and definition of a model which contemplate criteria and quality requirements specific to the SaaS.

The model is proposed based on various characteristics of the ISO 9126 standard along with the ITIL v3 and the framework COBIT 4.1, offering characteristics relating to a product of conventional software and a service of IT. The standard ISO 9126 has provided to the set welldefined characteristics of a software product, stating aspects of functionality, reliability, usability, efficiency, maintainability and portability. For its part, the ITIL v3 and the COBIT 4.1 were important elements for the identification of characteristics turned to the improvement of the management and quality of services for TI, in order to provide greater quality, particularly in relation to legal issues, performance and security in a SaaS product.

In addition of the support of those methodologies, the authors also were based on other work [8, $9,10]$, containing the vision of different authors, all in relation to the quality of SaaS systems. In order to give greater support and justification to this model, because of the lack of practical application, there was the need to give priority and complement the characteristics that have been raised.

The support were been done by means of a search online with various expert in the area, having as participants, managers, consultants, all of the area of SaaS. The search online was based on the sending of a checklist for the experts, where they have were able to analyze and indicate the relevance of each requirement raised. The relevance of the requirements of quality has indicated which characteristics are really important based on the knowledge and practical experience of the specialists. The relevance could be defined based on some criteria of trial [26]:

- Very Relevant: important features and of extreme importance to guarantee of their quality, interfering directly in quality internal and external of the SaaS products; 
- Relevant: important features mainly in to external quality of the system, impacting the final quality of the product;

- Little Relevant: characteristics desirable, but not essential for the success and operation of the application;

- Not applicable: characteristics that do not apply to the context SaaS. There are aspects of quality that are applicable and measurable in conventional software's, but not in the context SaaS, such as for example installation.

To help in the implementation and maintenance of the model proposed, while facilitating their understanding, has been defined a hierarchical structure in relation to the characteristics that have been raised. The hierarchical structure defined in this work resembles the proposed structure in the work of Hoffman et al. [27], in order to facilitate the verification of quality requirements that must be observed in the construction of a SaaS product. For the current work have been used three levels of hierarchy, each having a specific purpose. The three levels of this structure are submitted to follow:

- Level 1 - Criteria for Evaluation: Have been defined criteria to be observed during the evaluation of the quality in a SaaS system;

- Level 2 - Requirements (Guidelines): Formed by requirements of quality, representing guidelines specific for each criterion defined in the first level;

- Level 3 - Attributes of Verification: The third level is formed by the attributes of verification, in other words, measurable attributes that can be measured and punctuated.

In this way, the graphical representation of the model of quality proposed for the method "SaasQuality" was determined in accordance with the Figure 1.

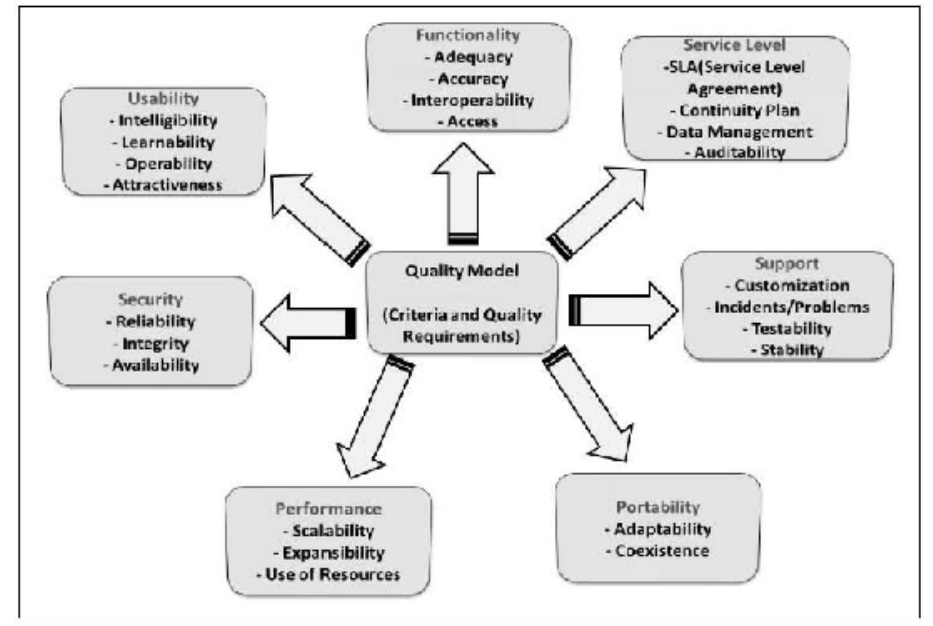

Figure 1 - Set of criteria and quality requirements specific to SaaS.

The following is presented with a summary of the main impact that the proposed requirements present in relation to SaaS systems.

Functionality: Through the use of architectures and technologies, a system SaaS provides a highinteroperability between systems, together with an efficient adequacy of their functions. 
Usability: The good quality in usability of a system can reduce the services within the support of the organization, thus allowing a good human interaction with the system, while avoiding problems of performance with the services.

Security: The need for cryptography, integrity and confidence in a SaaS approach requires attention detailed in its architecture. Many standards of the architecture SOA are being developed to give support to the safety, but the majorities are still immature [28].

Performance: a SaaS approach may have a negative impact on the performance of an application due to delays in the network and the burden of users in the same system. The contracting organization must design and assess the quantity of users that they will use the system. The supplier must design and carefully to assess their services by making sure that the performance requirements needed will be met.

Support: The ability to support in SaaS systems can provide a negative effect on the contracting company and provider. The testability can be affected negatively when using a large number of outsourced services.

Service Level: the contracting parties of SaaS systems can negotiate a SLA with his supplier, by providing agreements of levels of availability and sanctions for non-compliance of the agreement. The auditability can be negatively affected if the skills necessary to audit are not incorporated into the system.

Portability: the use of an approach SaaS must have a positive impact on the adaptability and portability when the adaptations are managed in an appropriate way, observing that the greater concern is associated with the portability of web browsers, not to operational systems.

\section{Presentation of SaASQuality}

The SaaSQuality was proposed and modelled following the logic of other evaluation methods $[29,30,31]$. All referenced work follow a generic structure, generally relying on a specific model of quality, along with a well-structured evaluation process. Figure 2 shows the overview of SaaSQuality.

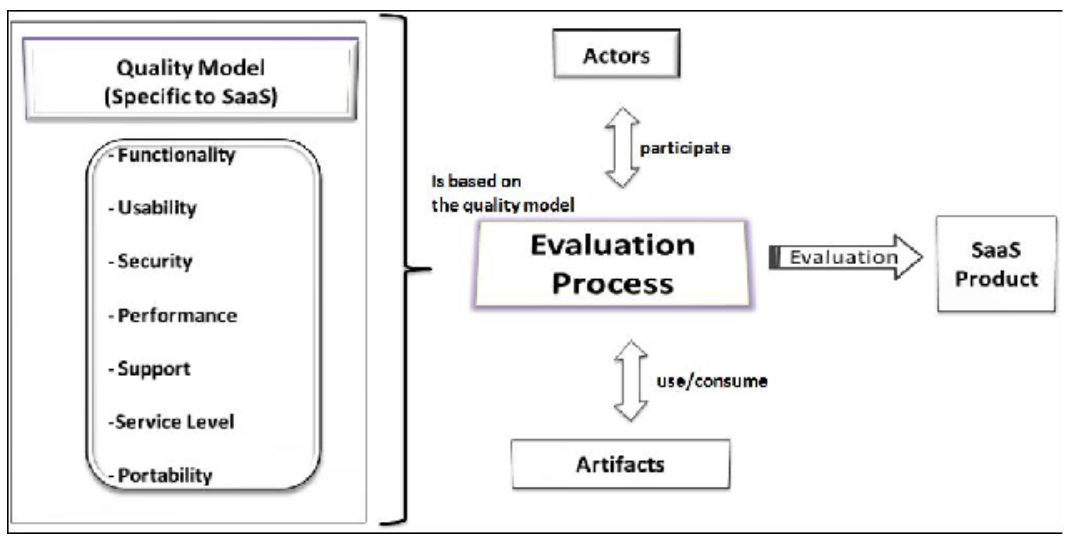

Figure 2 - Overview of SaaSQuality. 
For the subjectivity of the evaluation is minimal, ensuring greater efficiency, the process of SaaSQuality was developed following certain characteristics [4]:

- Repeatable: the process should enable the method to be applied several times in different instances and still have results that can be accepted as identical or similar;

- Reproducible: the process should contain specifications and steps, allowing the method to be applied by different evaluators (different entities) providing acceptable results to the context of evaluation;

- Impartial: the process should avoid that the results are influenced by internal or external factors in relation practical evaluation;

- Objective: the process should ensure clear results, avoiding ambiguities and different interpretations.

In the context of the current work, the actors represent roles that a human being plays in relation to the activities of the evaluation process. Basically there are four actors who participate in this process:

- Requester: Person/entity that calls for the assessment of a given product SaaS, specifying what are your goals and objectives;

- Evaluator: Person in which dominates all the guidelines for the application of the method SaaSQuality, serving as a guide and contact between the process and its participants.

- Users Interviewed: Participants that have the purpose to give critical views (positive and negative) in relation to quality aspects evaluated within the SaaS product;

- Specialist: Person who holds total knowledge in relation to the context of the application of system evaluated, in the case in question, the SaaS.

The actors performed activities present in stages of the evaluation process. The steps described below (Figure 3) are specific to the SaaSQuality, which were based on best practices and expertise required in the process of evaluation ISO/IEC 14598, but they have a simplification and a definition itself focused on systems SaaS, below a brief summary for each stage of the process.

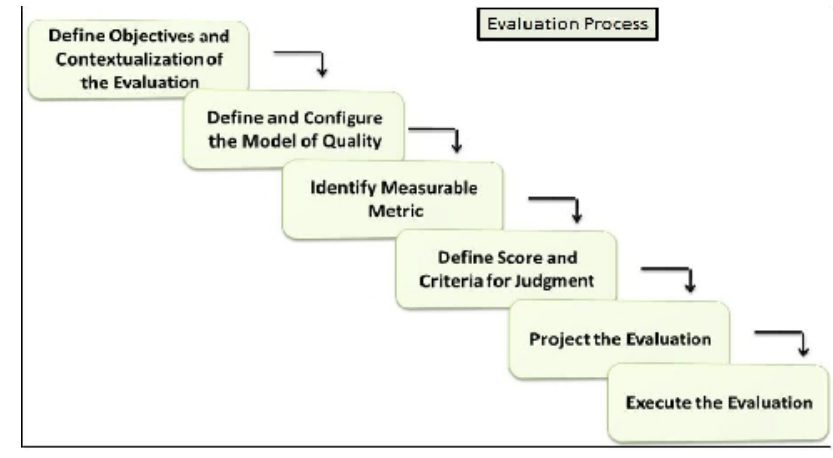

Figure 3 - Stages of the evaluation process.

1. Define Objectives and Contextualization of the Evaluation: The objective of this phase is clarify the purpose of the evaluation that will be held. The Requestor will specify the software to be evaluated together with the version and other necessary requirements.

2. Define and Configure the Model of Quality: After the definition of model of quality that will be used in practical assessments, at this stage must be performed to configuration of the same, specifying which criteria and quality requirements will be used; 
3. Identify Measurable Metric: This stage is based in the mapping of the characteristics of quality in measurable attributes, allowing their score and evaluation;

4. Define Score and Criteria for Judgment: In this stage will be set the numerical values for the attributes measurable, establishing criteria for judgment for the comparisons of the results obtained;

5. Project the Evaluation: In this stage should be defined the evaluation plan to be followed during the practical assessments, containing guidelines and procedures allowing an application structured and repeatable;

6. Execute the Evaluation: In the last stage of the process of evaluation, the Evaluator must use everything that was presented in previous stages, effecting the following activities: Obtaining Measures; Comparison with Criteria; and Judgment the Results.

Some of the stages presented may experience minor changes as a result of evaluations more specific, such changes will be made by the Evaluator and Specialist.

\section{RESULTS OF VALIDATION AND EVALUATION}

The validation of the research was carried out in two moments. It was initially applied a case study in relation to a SaaS product, providing a validation regarding the proposed method; and a comparative between the SaaSQuality and the MEDE-Pros was subsequently carried out with the purpose to identify similarities, differences and limitations between both methods.

\subsection{Case Study ("Salesforce CRM Sales")}

The case study was carried out by applying the SaaSQuality in relation to the product "Salesforce CRM Sales", a Customer Relationship Management (CRM) system that has the purpose facilitate and improve the relationship of the organizations and their respective customers. The following will be done the detailing of each step of the process of evaluation, relating them with the case study, identifying what was done at each stage of the process:

1-Define Objectives and Contextualization of the Evaluation: In the context of this work, the objective of the application of the method for the study of the case was to evaluate the SaaSQuality, in relation to your model of quality, process of evaluation and the techniques used. The expectation of the study is also assess the product "Salesforce CRM Sales", noting their compliances with requirements of quality.

2-Define and Configure the Model of Quality: The model of quality adopted in the practical assessments was the model proposed in the section "Quality Model for SaaSQuality" (Figure 1). This model has been chosen and used, because in addition to include a number of criteria relating to the evaluation of the quality of a system SaaS, it also presents a division of requirements (guidelines) and attributes of evaluation, by facilitating their use in practical assessments.

3-Identify Measurable Metric: At this stage there was the splitting of the requirements of quality in attributes that can be measured and punctuated. To realize this task, techniques and methodologies auxiliary staffs have been used to support and facilitate the identification of metric measurable. The technique used in this evaluation was the use of list of verification, in order to allow an efficient mapping of the requirements of the model of quality in attributes and measurable items.

The attributes measurable contained in the model of quality were raised by means of the knowledge of the Specialist, creating simple and objective questions allowing its evaluation and 
punctuation in the form of a checklist. On totals have been proposed 70 issues to be evaluated, the questions were decomposed in 7 (seven) different groups, related to the criteria of quality model, they are: functionality, usability, security, performance, support, service level, and portability.

The list of verification proposal for the evaluations added additional information in order to allow its use by the Evaluator in the form of a template for application. The additional information have been related and added to the list of verification, indicating, i.e., the average time elapsed in the evaluations, objectivity of the evaluation, definition of the local and the data collected, among other information, by facilitating the implementation and the control of the evaluations.

4-Define Score and Criteria for Judgment: The list of verification sets out for each criterion of quality 10 attributes in the form of questions, totalling a list of verification with 70 items. This number has been defined, as it makes it possible to build a full list the verification and at the same time is not exhaustive, because would damage the time in the implementation of the evaluations. The weighting given for each issue has been defined in the following way:

- Maximum value: "1" (highest score);

- Minimum value: "0" (lowest score).

For each criteria of quality have been carried out 15 assessments with different people, that is to say, different instances of assessments were performed, and obtained different notes in relation to the final quality of the criterion assessed.

At the end of all the 15 evaluations, thereby achieving 15 different values in relation to the quality of each criterion assessed, has been carried out the arithmetic mean of these values, to enable a better comparison of the results.

This process of obtaining the average of the quality, it was accomplished for 7 (seven) evaluation criteria, thus allowing the separation of the specific note of each criterion of the final note of the evaluated product, because it is interesting for the Requester of assessment identify the notes separately, checking which quality criteria are below the required level of quality, by making it possible to conduct a trial efficient together with adjustments and improvements.

For this judgment the authors were based on a lifting done at approximately 300 products of software's [32]. The criteria are based essentially on three levels: Superior, Medium and Lower, and can be viewed in Figure 4.

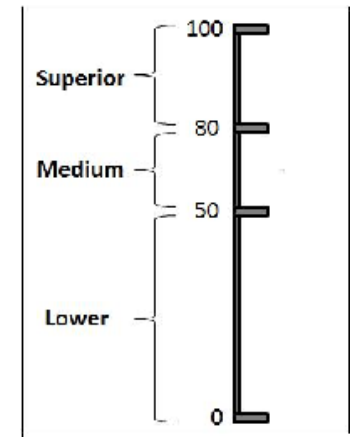

Figure 4 - Levels of quality of a product of software.

These criteria have been incorporated into the SaaSQuality, taking the following definitions and prospects of conclusion: 
- Superior level, the product of software should be in accordance with at least $80 \%$ of the quality requirements specified. This means that the note can vary from 100 to 80 , on a scale of 0 to 100 ;

- Medium level, the product of software should be in accordance with at least $50 \%$ of the quality requirements specified. This means that the note can vary from 80 to 50 ;

- Lower level, the product of software can have a note of 50 to 0 , by presenting a low level of quality.

5-Project the Evaluation: The projection of the practice evaluations were followed specific guidelines. The users interviewed during the evaluations were students with advanced knowledge in information technology, having to a certain way familiarity with the SaaS product assessed.

The time of each evaluation has been estimated and implemented between 40 to 50 minutes, trying not to overcome this time, to ensure a rapid assessment and practice. All the information and data raised by Users Interviewed were kept of possession only of the authors, thus ensuring confidentiality on the part of those interviewed. Information obtained does not have commercial value, only add value to the research and development of this work.

In total have been carried out 15 assessments with 15 different people. This number of assessments had objective improves it of the proposed method, together with the convergence of the data obtained. This is because initial assessments showed errors and details to be improved, both on the part of the model of quality and on the part of the process of evaluation.

6- Execute the Evaluation: Basically at this stage of the case study the Evaluator has executed three tasks:

- Collection of the measures;

- Comparison of the measures with criteria pre-defined, and finally;

- The judgment of the data obtained in the course of the evaluations.

In accordance with activities of obtaining of measures, all have been collected through the evaluations made by the Users Interviewed, making clear the impersonality of evaluator that was present only to doubts and perform the evaluation in a repeatable manner.

At the end of the evaluations, and early of activity de comparison of criteria, the numerical data have been treated and compared with the criteria, enabling a final judgment. The activity de judgment of the data has been made together with the development of a final report of evaluation. $\mathrm{O}$ objective to draw up a final report it is indicate the positive and negative points relating them to the quality criteria judged.

The report in addition to identify relevant aspects on the quality of the SaaS product, also identifies problematic aspects that occurred during the implementation of the evaluations, such as, for example, unavailability of the product, errors generated in the course of the evaluation, lack of information the product, among others.

7- Considerations and Results: On end of all the evaluations, the product has had a average note 76,6 in relation to the final quality, falls within the level "medium" of quality (Figure 6). 


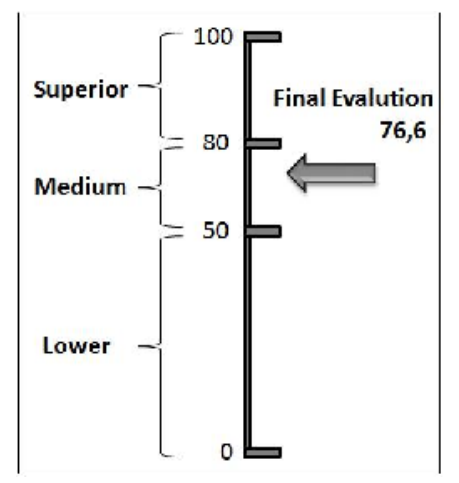

Figure 6 - The quality achieved by the "SalesForce CRM Sales"

Even by presenting a level "medium" of quality, not all the criteria of the evaluated product had notes unsatisfactory within the context SaaS (Figure 7).

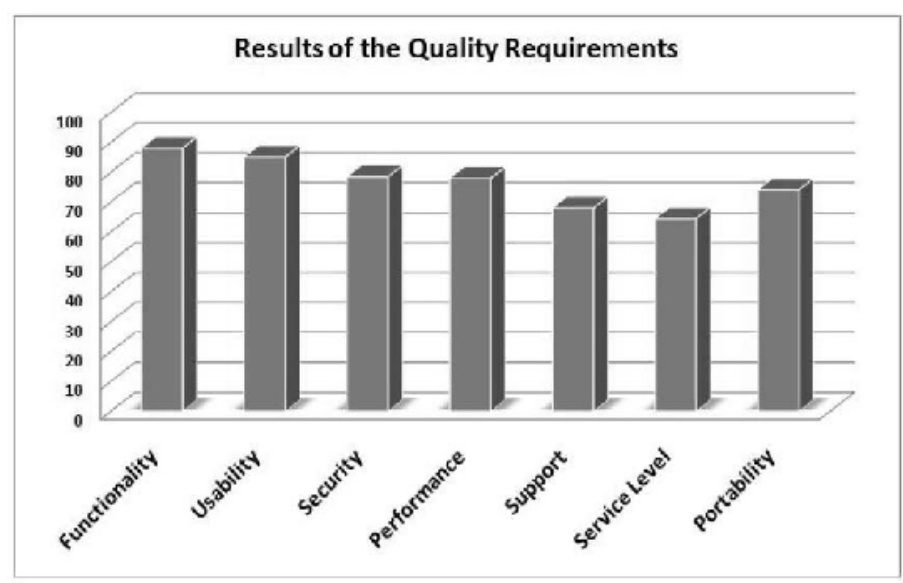

Figure 7 - Note assigned in relation to each criteria of quality.

One can conclude that, the requirements "Functionality" and "Usability" had the highest score in the evaluation performed, contemplating satisfactory levels of quality. Note also that these requirements are similar to that of a product of conventional software, not considering intrinsic characteristics of a system SaaS.

On the other hand, by examining the criteria "Support" and "Level of Service", it emerges that both have had the worst notes within the criteria evaluated, noting that they are characteristics aimed directly to a SaaS product. This result has a negative impact on the quality of the product, because both the criteria represent an important and great impact to the SaaS context, requiring studies and improvements in relation to your requirements, for example, aspects linked to SLA's, management of data, auditability, customization, stability, among others.

\subsection{Comparison with the method mede-pros}

This comparison has been drawn up with the aim of responding to some questions that can be raised the end of the case study. 
- What need for the development of a specific method for assessment of products SaaS?

- The conventional methods are not ready, and appropriate to assess a product SaaS?

- Which the similarities and differences of the SaaSQuality in comparison with conventional methods?

Trying to answer the questions above with good reason, adding additional information to the study of the case, it was carried out a comparative between methods SaaSQuality and MEDEPros. In order to achieve this comparative some steps have been followed, allowing the comparison between the data and results of both methods.

- Step 1: The first activity of comparative was the choice of a conventional method that will provide a practical assessment of the quality of a product of software, in the case of this research the MEDE-pros;

- Step 2: The second stage, was the study and the detail of the model of quality in which the MEDE-pros is based, based on requirements and quality attributes;

- Step 3: For the completion of the third stage, it was necessary to use a set of questions and checks (checklist) present in the book: "Quality of Product of Software" (Colombo \& Guerra, 2009). This checklist was drawn up in order to be applied to the directly MEDEpros;

- Step 4: The fourth stage makes reference to the application of the method MEDE-pros on the product "Salesforce CRM Sales";

- Step 5: At this stage, the data obtained in the evaluations with the MEDE-pros were compared with the data obtained in the study of the case by the SaaSQuality.

At the end of the comparative, with the data analyzed and interpreted, a graphic of the type "radar" was mounted (Figure 8), was plotted the values of each criteria of quality in the course of the axes, represented by the two methods (SaaSQuality and MEDE-pros).

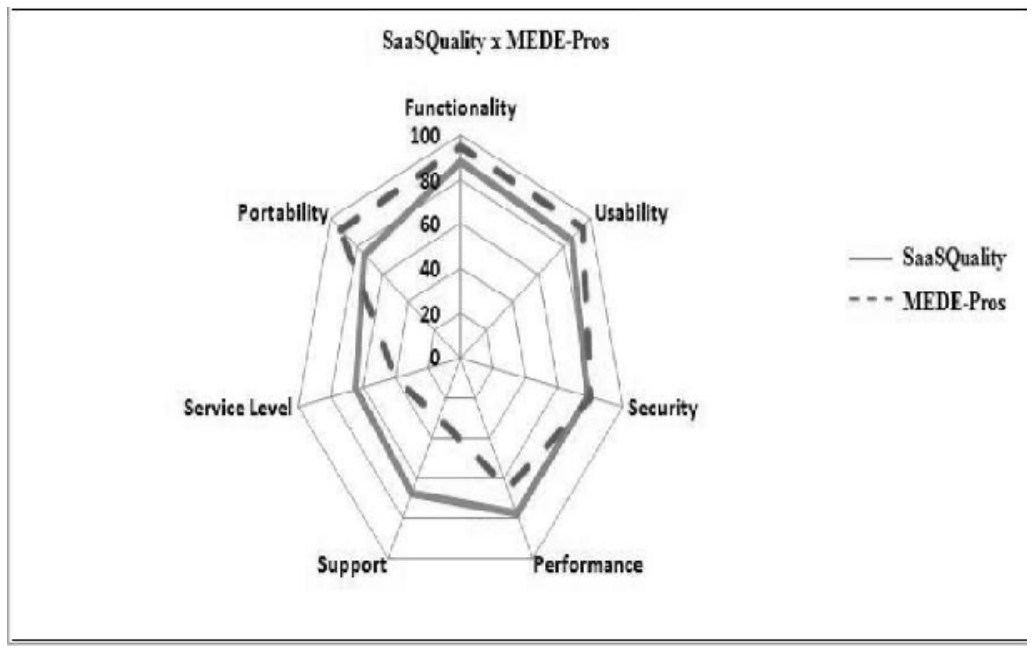

Figure 8 - The result of the comparative of quality criteria (SaaSQuality vs MEDE-pros)

In accordance with the Figure 8, what is observed is the convergence and the divergence of the data in relation to the criteria of quality. Functionality, Usability and Security, have had a great convergence of data in relation to methods. This is due to the fact of that both in conventional 
systems such as the SaaS those quality criteria are similar. Below follows a small description of these similarities.

Functionality: If it seems mainly in the aspects of interoperability, access, and accuracy, thus enabling the guarantee of functions that follow the needs of customers, correctly and accurately, together with the possibility of integration with other systems legacies of the organization.

Usability: The requirements operability and attractiveness are necessary in computing systems, it is extremely importance to a greater user satisfaction.

Security: Even having a greater impact on the paradigm SaaS, security aspects are very important in systems conventional, especially systems that work with critical data of business organizations, requiring greater reliability, integrity and availability for these data.

The Portability criterion also had a convergence the data in both methods, however, this feature presents an application context quite different in both cases. On SaaS, the portability criterion is more focused for browsers and the doors of communication. Already in the conventional systems to portability is more related to operating systems and distributions. In other words, the data obtained even if they are converging, cannot be considered to be similar, because, the coexistence requirements and adaptability have applicability well different in both the paradigm.

The criterion Performance has had a small difference in the data, but it was something already expected, because the SaaS systems due to their way of access, by means of tenants and multitenants have distinct characteristics in scalability of their users and in expansibility of new services to the system $[33,34]$.

The Service of Level and Support have had the greatest divergences in the results. The reason is due to the fact that the quality requisites are influenced directly by features of the IT service management, not covered by standard ISO 9126, such as, for example, customizations; management of incidents and problems; SLA; plans of continuity; management of data; and auditability. Below, the main points of the analysis of these requirements.

The Service of Level can't be measured by the method MEDE-pros, because for conventional systems (different of the SaaS), features such as SLA's, management of data, plans of continuity, among others, are not included in model of quality the method MEDE-pros;

The Support had a good relationship between the characteristics of testability and stability, however, when it comes to incidents and personalization, the characteristics of the SaaS and conventional systems are quite different, thus causing differences between the evaluations of both methods.

At the end of comparisons is concluded that, from the comparisons made, it is clear that a conventional method is not entirely appropriate for evaluations of products SaaS. Some of the characteristics were been well evaluated by the method MEDE-pros, but others have had their assessment impaired, because of the context in which they were being employed. This is due to the fact, among other factors, the use of the model of quality.

\section{Conclusions}

This paper has put forward a proposal for the development of a method for assessing the quality of a product of Software as a Service (SaaS), known as SaaSQuality. The proposed method was 
based on a model of specific quality to the SaaS paradigm, by proposing a process of evaluation own, simple and effective.

For the construction of the specific model to the SaaS paradigm, allowing its use in practice by the SaaSQuality, there has been an integration between criteria and principles of methods of assessment of the quality of the product of software, with criteria of methods of management de services de TI.

The criteria defined has enabled the lifting and the impact of quality criteria specific to the SaaS context, dividing them into groups of characteristics and sub-characteristics, in order to show its impact both positive and negative to this new paradigm.

The model of quality is a compilation of the main features present in a product of software and a service of IT. The evaluations performed by the method in question were carried out by means of a list of verification (checklist), contemplating through measurable attributes the score and measurement of quality requirements.

At the end of the research the authors highlight aspects important allowing the extension of studies on future work. The first point with regard to the proposal of a method to assess and assist the guarantee of quality in relation to process of development of a product SaaS.

The second approach with regard to the measurement of the SaaSQuality as to the quality in use. During the definition of the problem has been given a greater emphasis on the internal quality and foreign.

Finally, the third refers to supplement and deepening of the list of verification (checklist). In the present paper, emphasis was given in attributes that provide a general assessment of the quality of a SaaS product; all these attributes have been assessed with the same weight and punctuations.

\section{ACKNOWLEDGEMENTS}

The authors thank The Coordination for the Improvement of Higher Level or Education (CAPES) and The National Council of Technological and Scientific Development (CNPq) for their financial support.

\section{REFERENCES}

[1] Kan, S. H. (2002). Metrics and Models in Software Quality Engineering. Addison-Wesley.

[2] Akella, P. S.; Rao, K. N. (2011) Effective Independent Quality Assessment Using IV\&V. International Journal of Computer Science and Information Technology (IJCSIT), Vol 3 (3), 320-332.

[3] Krishna, P.; Rao, R. (2011) Software Quality Assurance in CMM and XPA Comparative Study. International Journal of Computer Science and Information Technologies (IJCSIT), Vol. 2 (6) , 29152919.

[4] Lew, P.; Zhang, L.; Wang, S.; Jiang, W. (2008). Guidelines to Determine Quality for Web-Based Software Applications. In: Computational Intelligence for Modelling Control \& Automation,p 709, IEEE Publications, Vienna, Austria.

[5] Colombo, R. M. T.; Guerra A. C. (2009). Information technology: Quality of Product of Software, MCT/SEPIN.

[6] Barney, S.; Wohlin, C. (2009). Software Product Quality: Ensuring a Common Goal. Lecture Notes in Computer Science 3(5), 256-267.

[7] Auer, T. (1998). Quality of IS use. European Journal of Information Systems 7(9), 192-201.

[8] Dubey, A.; Wagle, D. (2006). Delivering software as a service. The McKinsey Quarterly 3(5),1-12. 
[9] O’Brien, L.; Bass, L.; Merson, P. (2005). Quality attributes and service-oriented architectures. Technical report, Carnegie Mellon University.

[10] Havelka, D.; Sutton, S. G.; Arnold, V. (1998). A methodology for developing measurement criteria for assurance services: An application in information systems assurance. Journal of Practice and Theory 8(5),80-87.

[11] Jureta, I. J.; Herssens, C.; Faulkner, S. (2009). A comprehensive quality model for service-oriented systems. Software Quality Control 7(4), 65-98.

[12] Cancian, M. H. (2009). A proposal of reference guide for providers of software as a service. Dissertation in Automation and Systems Engineering, University Santa Catarina.

[13] Cancian, M. H.; Rabelo, R.J.; Wangenheim, C. G. V. (2009). A proposal for drawing up of the contract for Level of Service to Software as a Service (SaaS). In 8th International Information and Telecommunication Technologies Symposium, p 410, IEEE Publications, Florianópolis, Brasil.

[14] Rosenberg, F.; Leitner, P.; Michlmayr, A. P. C.; Dustdar, S. (2008). Towards composition as a service-a quality of service driven approach. Dstributed Systems Group.

[15] Silva, E. M.; Yue, G. K.; Rotondaro, R. G.; Laurindo, F. J. B. (2006). Management of the quality of services for IT:in search of competitiveness. Magazine Production 2(6), 329-340.

[16] Miguel, P. A. C.; Salomi, G. E. (2004). A review of the models for measurement of the quality of services. Magazine Production 10(1), 12-30.

[17] Jung, C. F. (2004). Methodology for research and development: applied to new technologies. Axcel Books Publishing House.

[18] Wohlin, C.; Runeson, P.; Host, M.; Ohlsson, M. C.; Regneel, B.; Wesslén, A. (2000). Experimentation in software engineering: An introduction. Kluwer Academic Plublishers.

[19] ISO/IEC 9126. (1991). The international organization for standardization. Software engineering Product quality.

[20] ITIL v3. (2008). Information technology infrastructure library. Publications Service Management.

[21] TGI. (2007). Information technology governance institute. COBIT 4.1: Control objectives, Management guidelines, Maturity models. Rolling Meadows: ITGI.

[22] ISO/IEC 14598-5. (1997). International standard. information technology - software product evaluation - part 5: Process for evaluators.

[23] Duarte Filho, N. F.; Padua, C. I. P. S.; Zambalde, A. L.; Bermejo, P. H. S. (2010). Quality attributes for SaaS's products. In: 5th Iberian Conference on Information Systems and Technology, p 80, IEEE Publications, Santiago de Compostela, Spain.

[24] Boehm, B. W. (1981). Software engineering economics. Prentice-Hall.

[25] Gatti, M. A. C.; Werneck, V. B. (2004). Quality requirements of web applications. Available at: http://www.ime.uerj.br/cadernos/cadinf/, Accessed in 2 September, 2011.

[26] Farbey, B. (1991). Exploring Requirements: Quality Before Design. European Journal of Information Systems 1(3), 145-147.

[27] Hoffman, M.; Kuhn, N.; Weber, M.; Bittner, M. (2004). Requirements for requirements management tools. In: 12th IEEE International Requirements Engineering Conference, p 165, IEEE Publications, Kyoto, Japan.

[28] Ma, D. (2007). The business model of 'software-as-a-service'. In: International Conference on Services Computing, p 701, IEEE Publications, Hawaii, USA.

[29] Colombo, R.; Guerra, A. (2002). The evaluation method for software product. In 19th International Conference on Software and Systems Engineering and their Applications, p 143, IEEE Publications, Paris, França.

[30] Guerra, A. C.; Colombo, R. T.; Aguayo, M. T. V.; Peres, R. D. (2007). Model of quality of components of software. In: Conference IADIS Ibero-Americana, p 231, Vila Real, Portugal.

[31] MEDE-PROS. (1996). Method for assessing the quality of software product. Center for Information Technology Renato Archer-CTI/MCT.

[32] Martinez, M. R. M. (1999). The software product evaluation data base -supporting mede-pros. In: International Software Engineering Standards Symposium, IEEE Publications, Curitiba, Brazil.

[33] Chong, F.; Carraro, G.; Wolter, R. (2009). Multi-tenant data architecture. Available at: http://msdn2.microsoft.com/, Accessed in 15 December, 2011.

[34] Choudhary, V. (2007). Softwares as a services: Implications for investment in software development. In 40th Annual Hawaii International Conference on System Sciencies, p 58, IEEE Publications, Hawaii. 


\section{Authors}

Nemésio Freitas Duarte Filho: Graduation in Computer Science from the Federal University of Lavras, and master's degree at the Federal University of Minas Gerais. Has experience in Software Engineering, Governance, and IT Management. Has certification in the areas of IT governance and business process modelling (ITIL v2, COBIT 4.1 and OCEB Fundamental-OMG)

Clarindo Isaias Pereira da Silva e Pádua: Graduation in Electrical Engineering from the Federal University of Minas Gerais, master's in Computer Science from the Federal University of Minas Gerais and doctorate in Computer Science - University of Southampton. Has experience in Computing Systems, working mainly in the areas of Software Engineering and Usability Engineering.

Paulo Henrique de Souza Bermejo: Adjunct Professor of the Department of Computer Science of the Federal University of Lavras. Doctorate in Knowledge Engineering and Management by the Federal University of Santa Catarina. Is certified in IT Governance framework (Cobit) and representative (advocate member) of ISACA.

Andre Luiz Zambalde: Graduation in Electrical Engineering Telecommunications from the National Institute of Telecommunications in Santa Rita do Sapucaí, master's at Electric Engineering from University Federal de Itajubá and doctorate in Computer Science from University Federal do Rio de Janeiro. Has experience in information technology in education, distance learning and information systems.

Urlan Salgado de Barros: Master's Degree in Computer Science from the University Federal do Paraná. Graduation in Computer Science from the Federal University of Lavras. Has experience in the area of Computer Science, with emphasis in Computer Networks and Computer Security. 